\title{
DESEMPENHO DE ARGAMASSAS DE REVESTIMENTO PRODUZIDOS A PARTIR DE ESCÓRIA DE ACIARIA
}

\author{
MATIAS, ANA CAROLINA DE PAULA \\ Mestranda em Engenharia Civil \\ Universidade Federal de Ouro Preto \\ Minas Gerais; Brasil \\ ana.carolina.p.matias@gmail.com
}

FIGUEIREDO, ALINE SANTANA

Mestranda em Engenharia Civil

Universidade Federal de Ouro Preto

Minas Gerais; Brasil

alinesantanafigueiredo@gmail.com

\author{
DE CARVALHO, JOSÉ MARIA FRANCO \\ Engenheiro Civil, D.Sc \\ Universidade Federal de Viçosa \\ Minas Gerais; Brasil \\ jmfcarvalhoii@gmail.com
}

\author{
ANDRADE, HUMBERTO DIAS \\ Doutorando em Engenharia Civil \\ Universidade Federal de Ouro Preto \\ Minas Gerais; Brasil \\ andrade.hdias@gmail.com \\ CAETANO, MARINA ALTOÉ \\ Mestranda em Engenharia Civil \\ Universidade Federal de Ouro Preto \\ Minas Gerais; Brasil \\ altoemarina@gmail.com
}

\author{
Engenheiro Civil, D.Sc \\ Universidade Federal de Ouro Preto \\ Minas Gerais; Brasil \\ fiorotti.ricardo@gmail.com
}

PEIXOTO, RICARDO ANDRÉ FIOROTTI

\begin{abstract}
RESUMO
A preocupação com o meio ambiente e a escassez de recursos naturais têm levado à pesquisa de novos materiais e à incorporação de resíduos como matérias-primas alternativas para execução de matrizes cimentícias. Este trabalho propõe a produção de argamassas para revestimento de alvenarias produzidas integralmente com escória de aciaria. Foram produzidas misturas com agregados obtidos da fração não metálica destas escórias e misturas referência usando areia natural de rio; uma vez que as matrizes alternativas devem apresentar desempenho similar às convencionais. Para atestar a possibilidade de uso como argamassa de revestimento, foram realizados ensaios para determinação da massa específica, retenção de água, resistência à compressão e à tração na flexão, além de ensaios de carbonatação e durabilidade. Adicionalmente, para avaliação da adesão inicial destas matrizes, foi criado um procedimento operacional padrão, devido à ausência de normatização própria para realização desse ensaio.
\end{abstract}

Palavras-chave: Argamassa de Revestimento, Escória de Aciaria, Matrizes Cimentícias Sustentáveis, Agregado Reciclado, Ensaio de Adesão Inicial

\begin{abstract}
The concern with the environment and the scarcity of natural resources have led to the search for new materials and the incorporation of waste as alternative raw materials for the execution of cement-based composites. This work proposes the production for masonry coating produced entirely with steel slag. Coating mortars were produced with aggregates obtained from the non - metallic fraction of the steel slag. Reference mortars with natural river sand were also produced, as testimony; whereas to ensure good applicability, alternative matrices must perform similarly to conventional ones. To certify the possibility of use as mortar, tests were performed to determine the specific gravity, water retention, resistance to compression and traction in flexion, in addition to carbonation and durability tests. Additionally, to evaluate the initial adhesion of these matrices, a standard operating procedure was created, due to the absence of a specific standard to perform this test.
\end{abstract}

Keywords: Coating Mortar; Steel slag; Sustainable Cementing Matrices; Recycled Aggregate; Initial Adhesion Test 


\section{INTRODUÇÃO}

Com o avanço tecnológico crescem o número de indústrias e, portanto, o volume de resíduos sólidos advindos de seus mais diversos processos. Sem destinação adequada, esses resíduos são muitas vezes descartados em locais impróprios ficando expostos ao ambiente. No setor siderúrgico, por exemplo, o total de subprodutos e resíduos gerados no Brasil no biênio 2017-2018 foi de $607 \mathrm{~kg} / \mathrm{t}$ de aço bruto produzido, dos quais $27 \%$ foram de escória de aciaria (EA). Ou seja, foram gerados, aproximadamente, 5,6 milhões de toneladas de EA, dos quais 14\% (790 mil toneladas) foram destinados para estoque ou disposição final (IABR, 2018). Frente a esta realidade, faz-se necessário acelerar o desenvolvimento de métodos de gestão de resíduos sólidos industriais.

Muitos estudos vêm sendo desenvolvidos no sentido de utilizar estes resíduos como matéria-prima para produção de material utilizável (GEYER 2001; SOUZA, 2007; SILVA, 2011; TOFFOLO,2015). A reciclagem dos resíduos industriais através de estudos capazes de detectar sua potencialidade e viabilizar sua seleção preliminar é encarada hoje como atividade que pode contribuir para diversificação dos produtos, diminuição dos custos, além de resultar em "novas" matérias-primas para uma série de setores.

Ao considerar-se a demanda de recursos naturais e sabendo-se que o desenvolvimento tecnológico da indústria da construção civil requer novas tecnologias eficientes, competitivas e de baixo custo, a adoção de materiais sustentáveis surge como alternativa técnica, econômica e ambientalmente viável. Para analisar o comportamento das misturas produzidas frente a suscetibilidade a manifestações patológicas, foram realizados ensaios de carbonatação e durabilidade, para previsão do comportamento dessas matrizes a longo prazo. Para Moura (2007) a qualidade de um sistema de revestimento está diretamente ligada às características de salubridade, conforto e durabilidade que ele apresenta.

Portanto, com o intuito de difundir o uso de materiais não convencionais visando a sustentabilidade, o presente trabalho propõe a investigação das propriedades de argamassas de revestimento produzidas inteiramente com agregados reciclados de escória de aciaria.

\section{PROGRAMA EXPERIMENTAL}

\subsection{Materiais}

Foram utilizados os seguintes materiais: cimento CP-IV-32-RS, cal hidratada (tipo CHI), agregados miúdos, aditivo incorporador de ar (LAS - detergente doméstico) e água potável. Os agregados miúdos incluem areia de rio (agregado natural, AN, como referência) e escória de aciaria (EA). Antes da mistura, os agregados naturais e os resíduos foram passados na peneira de malha $2.36 \mathrm{~mm}$ e secos em estufa à $105^{\circ} \mathrm{C}$.

A EA usada no presente trabalho é proveniente de aciaria elétrica e foi enviada pela ROLTH DO BRASIL, com granulometria inferior a $2,36 \mathrm{~mm}$ e foram processadas em sistema de recuperação de metálicos por tamboramento no Laboratório de Materiais de Construção Civil - $1 \mathrm{mc}^{2} /$ DECIV/EM/UFOP, em equipamento INBRAS (HFCC $\phi 12$ "X12") com intensidade de campo 1500 GAUSS e frequência de vibração de 60 HERTZ. A areia natural de rio utilizada como agregado é composta basicamente por sílica, sendo de procedência do município de Ponte Nova, Minas Gerais, Brasil e foi utilizada em estado bruto.

O cimento do tipo CP-IV-32-RS foi escolhido por sua boa disponibilidade e custo acessível. Além disso, o teor de pozolanas contidos nesse tipo de cimento reduz as reações com agregados reativos e possibilidade de manifestações patológicas associadas, o que é benéfico quando se utiliza a EA como agregado. Destaca-se também seu baixo calor de hidratação, favorecendo manuseio e atividades realizadas para acabamentos de argamassas de revestimento.

Adotou-se como aditivo incorporador de ar o detergente neutro, estudado e proposto por Mendes et al. (2017). Segundo a Ficha de Informações de Segurança de Produtos Químicos, o produto é composto por uma associação de tensoativos aniônicos entre 6 e 10\%, compreendendo LAS (CAS: 25155-30-0); Linear Alquil Benzeno Sulfonato de Trietanolamina (CAS: 27323-41-7) e Lauril Éter Sulfato de Sódio (CAS:9004-82-4).

Os agregados desenvolvidos foram ajustados conforme parâmetros estabelecidos pela British Standards - BS 1200 (1976), considerando distribuição granulométrica mais adequada para produção de argamassas para revestimento de alvenarias. As curvas utilizadas para as areias de escória foram projetadas de maneira a incluir percentual de finos que atuariam como ligantes, contribuindo para maior trabalhabilidade das argamassas no estado fresco. A Figura 1 apresenta os limites 
indicados pela normalização BS 1200 (1976); os limites máximos e mínimos aceitáveis bem como os limites ótimos preconizados pela NBR 7211 (ABNT,1987).

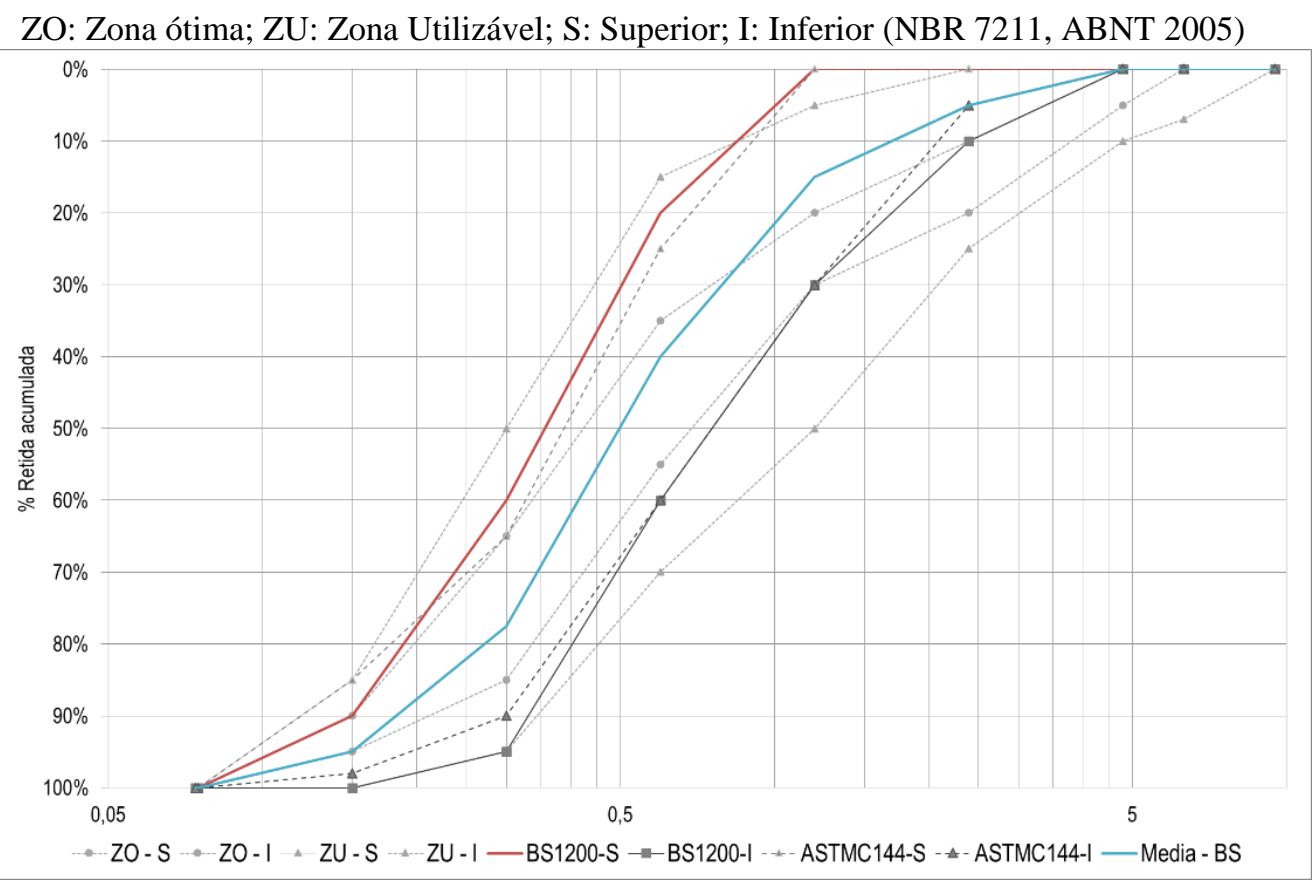

Figura 1. Faixas granulométricas adotadas para produção das areias

\subsubsection{Caracterização dos materiais}

A massa específica das areias foi determinada usando frasco tipo Chapman, de acordo com a NBR 9776 (ABNT, 2003). Para tornar mais fácil o entendimento das siglas utilizadas neste trabalho, estas e a faixa granulométrica correspondente são apresentadas na Tabela 1.

Tabela 1. Nomenclatura utilizada para as areias

$\begin{array}{ccc}\text { Tipo de areia } & \text { Sigla } & \text { Faixa granulométrica adotada } \\ \text { Areia natural de rio } & \text { AN } & \text { Média BS } 1200 \\ \text { Areia de Escória } & \text { AEM } & \text { Média BS } 1200 \\ \text { Areia de Escória } & \text { AES } & \text { Superior BS } 1200\end{array}$

A caracterização química da EA foi realizada pelo método de Fluorescência de Raio-X (FRX). O FRX apresentou uma análise semi-quantitativa de energia dispersiva, utilizando o equipamento PANalytical Epsilon 3X, instrumentado com anodo de prata $(\mathrm{Ag})$, excitação $50 \mathrm{KV}$, corrente máxima $1 \mathrm{~mA}$, potência máxima $9 \mathrm{~W}$.

\subsection{Produção das argamassas}

Para produção das argamassas, foram adotadas duas composições (em volume): 1:1:6 e 1:0:6 (cimento: cal: agregado miúdo). As misturas produzidas foram aditivadas com incorporador de ar à base de LAS nas concentrações $0,15 \%$ e 0,20\%. As composições foram nomeadas conforme o tipo de areia utilizado e a concentração de LAS adotada, conforme resumido na Tabela 2 .

As argamassas foram produzidas segundo procedimento da NBR 13276 (ABNT, 2016). A relação de água/aglomerantes foi definida como a necessária para mistura ter um índice de consistência de $260 \pm 5 \mathrm{~mm}$. Para cada tratamento proposto, foram moldados 3 corpos de prova (CPs) prismáticos 40x40x160mm. A cura foi realizada em câmara úmida por 28 dias; temperatura $25 \pm 2^{\circ} \mathrm{C}$ e umidade relativa de $90 \% \pm 5 \%$. 


$\begin{array}{ccccccc}\text { Composição } & \text { Cimento } & \text { Cal } & \text { (AN) } & \text { (AEM) } & \text { (AES) } & \text { [LAS] } \\ \text { 1:1:6AEM15 } & 1 & 1 & - & 6 & - & 0,15 \% \\ \text { 1:0:6AEM20 } & 1 & 0 & - & 6 & - & 0,20 \% \\ \text { 1:0:6AES20 } & 1 & 0 & - & - & 6 & 0,20 \% \\ \text { 1:1:6AN15 } & 1 & 1 & 6 & - & - & 0,15 \% \\ \text { 1:0:6AN20 } & 1 & 0 & 6 & - & - & 0,20 \%\end{array}$

Tabela 2. Composições produzidas

No estado fresco, foram estimadas qualitativamente propriedades reológicas para cada mistura. Além disso, foram determinados: massa específica e retenção de água, preconizado pelas NBR 13278 (ANBT, 2005) e NBR 13277 (ABNT, 2005), respectivamente. O ensaio para determinação da adesão inicial foi realizado segundo procedimento desenvolvido para execução do presente trabalho, devido à ausência de normatização própria para realização deste tipo de teste. Este protocolo foi tomado como procedimento operacional padrão (POP) no Laboratório de Materiais de Construção Civil $\mathrm{lmc}^{2} / \mathrm{DECIV} / \mathrm{EM} / \mathrm{UFOP}$. A determinação da adesão inicial de argamassas de revestimento é essencial para avaliação do potencial de deslocamento e desplacamento: manifestações patológicas comuns para este tipo de argamassa.

Para execução desta técnica, procedeu-se da seguinte forma: (a) pesagem do conjunto argamassa+cuba (tendo-se conhecida a tara da cuba); (b) lançamento da argamassa, com auxílio de colher de pedreiro (tamanho 8) sobre um substrato padrão (previamente molhado), a uma distância de $30 \mathrm{~cm}$. O lançamento é feito com movimentos de punho, em sentido ascendente, conforme indicado na Figura 2.
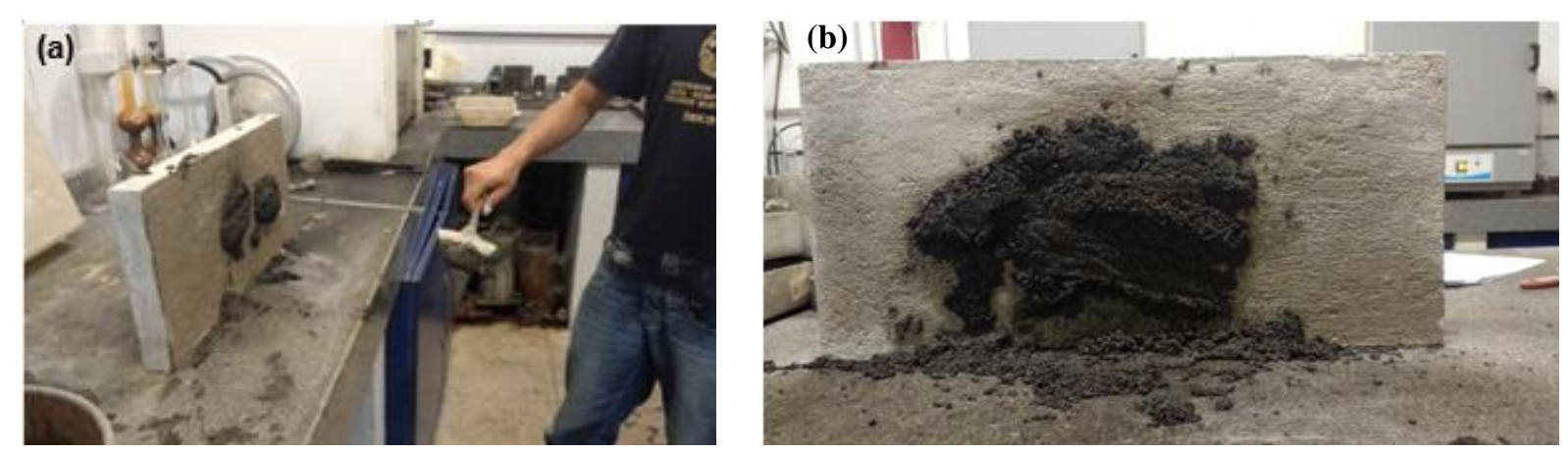

Figura 2. Ensaio de adesão inicial. (a) lançamento da argamassa. (b) material aderido ao substrato e "rebote"

O material não aderido ao substrato, denominado "rebote", também deve ser pesado. De posse da massa de argamassa antes do lançamento e da massa da argamassa do "rebote", calcular a adesão inicial utilizando-se a Equação 1. A adesão inicial é determinada, portanto, pela porcentagem de material que ficou aderido no substrato padrão.

$$
\text { Adesão inicial }=\left(1-\frac{\text { "rebote" }}{\text { material lançado }}\right) * 100
$$

No estado endurecido, foram realizados os ensaios de resistência à compressão e à tração na flexão, ensaios de absorção de água por imersão e índice de vazios, segundo determinado pelas NBR 13279 (ABNT, 2005) e NBR 9778 (ABNT, 2005), respectivamente. Para avaliação do comportamento das matrizes produzidas a longo prazo foram realizados ainda o ensaio para determinação da durabilidade utilizando-se método acelerado ou método da variação de comprimento de barras de argamassa, segundo preconizado pela NBR 15577-4 (ABNT, 2009) e ensaio de carbonatação, segundo normalização francesa XP P18-458 (AFNOR, 2008). Para o ensaio de carbonatação foram moldados 3 corpos de prova de dimensões $5 \times 10 \mathrm{~cm}$ para cada tratamento adotado. Após 28 dias de cura, os CPs foram retirados da câmara úmida e passaram pelo seguinte protocolo: regularização da superfície das extremidades, aplicação de parafina líquida nas faces laterais, fita adesiva nestas mesmas faces e em uma das faces circulares; deixando a outra face circular livre para carbonatar. Para realização do ensaio, os CPs foram acondicionados em incubadora (Shel Lab, modelo $2428 \mathrm{H}$ ) com parâmetros ajustáveis para umidade, temperatura e concentração de $\mathrm{CO}_{2}$ apresentados na Tabela 3. Após 100 dias na incubadora, os CPs foram fraturados diametralmente e logo após foi aspergida solução de fenolftaleína para verificação do $\mathrm{pH}$ da matriz cimentícias. Vale ressaltar que a fenolftaleína se mantém incolor em soluções ácidas e torna-se rosada em soluções básicas. 
Tabela 3. Parâmetros aplicados para ensaio de carbonatação

$\begin{array}{cc}\text { Concentração de } \mathrm{CO}_{2} & 8 \% \\ \text { Temperatura } & 25 \pm 1{ }^{\circ} \mathrm{C} \\ \text { Umidade } & 50-60 \%\end{array}$

\section{RESULTADOS E DISCUSSÃO}

\subsection{Caracterização dos materiais}

As areias AEM e AN apresentaram valores para dimensão máxima característica (DMC) de 2,4 mm e módulo de finura (MF) igual a 2,33; enquadrando essas areias na zona ótima, segundo NBR 7211 (ABNT, 2005). Para a AES a DMC foi igual a 0,6mm e o MF 1,7 e esta pertence à zona utilizável inferior segundo normatização preconizada.

Os resultados de FRX mostraram que a EA inclui principalmente óxidos de cálcio ( $\mathrm{CaO}-49.1 \%)$, ferro $\left(\mathrm{Fe}_{2} \mathrm{O}_{3}-24.1 \%\right)$ e silício $\left(\mathrm{SiO}_{2}-14.3 \%\right)$. Tais resultados estão em concordância com os obtidos por outros autores que estudaram materiais semelhantes (TOFFOLO, 2015; SOUZA, 2015; POLESE,2007). Destaca-se o fato de a presença de altos teores de $\mathrm{Fe}_{2} \mathrm{O}_{3}$ e outros óxidos metálicos influenciar diretamente no aumento da massa específica do agregado e da argamassa produzida a partir do mesmo.

De acordo com a Figura 3, a alta massa específica das areias produzidas a partir de escória de aciaria (AEM e AES), em comparação com a areia natural de rio (AN) é consequência da sua composição química. Essas propriedades, em conjunto com a forma das partículas, influenciam na morfologia das matrizes no estado fresco e endurecido.

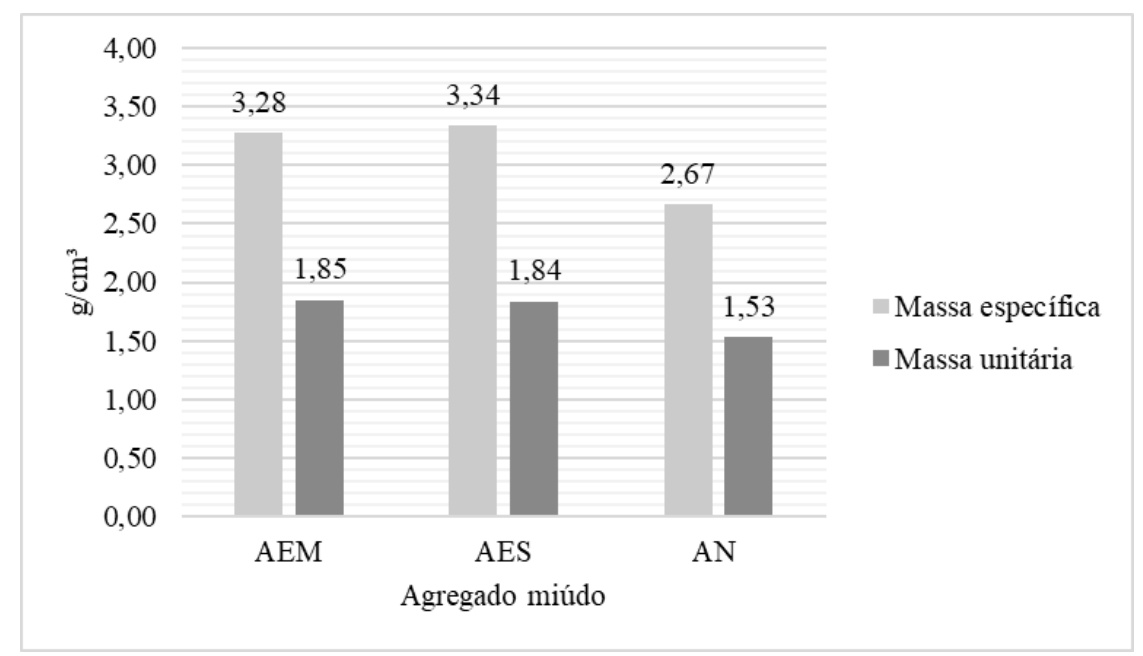

Figura 3. Massa unitária e massa específica das amostras

\subsection{Caracterização das argamassas}

\subsubsection{Estado fresco}

Conforme ilustrado à Figura 4(a), as argamassas apresentaram coesão adequada, boa distribuição das fases constituintes e capacidade de manter seus materiais componentes homogêneos sem segregação ou exsudação. Na Figura 4(b) que ilustra propriedades tixotrópicas, observou-se experimentalmente que as argamassas produzidas exigiram baixa energia para que se produzissem alterações em sua forma, e depois destas alterações de forma, as argamassas mantiveram-se estáveis mesmo sob ação da gravidade, fator muito importante para aplicabilidade das argamassas obtidas como produto. 

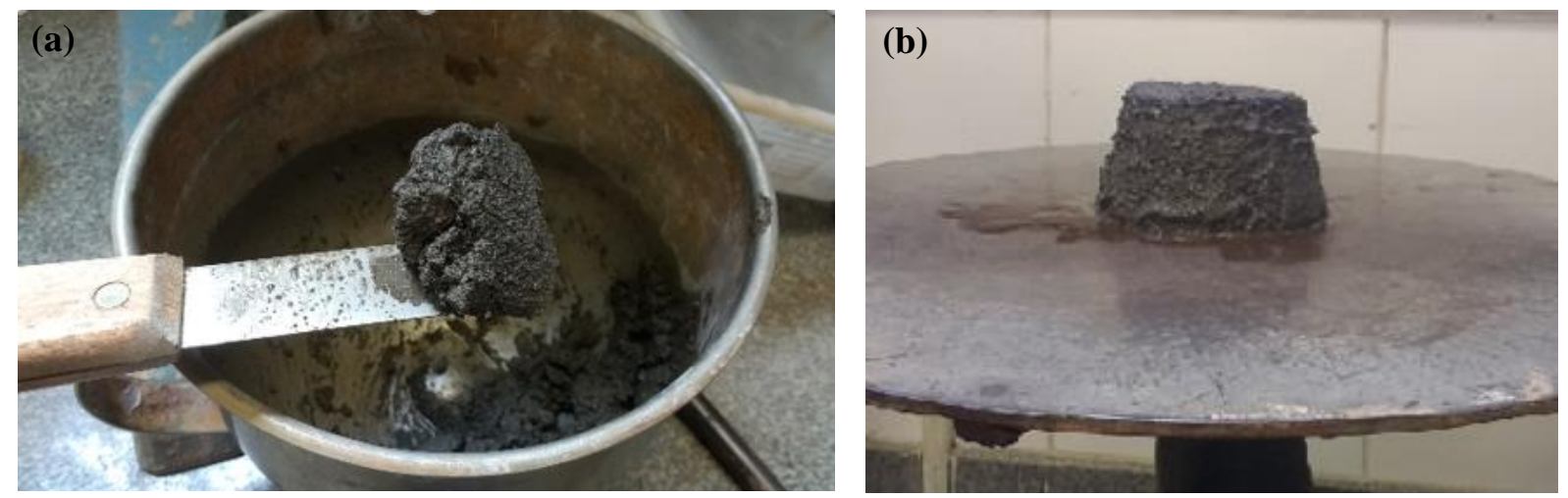

Figura 4. Argamassas produzidas com areia de escória, evidenciando boa coesão

Para o ensaio de massa específica, observou-se a diminuição da mesma com o aumento do teor de LAS (Figura 5). Essa redução se deve a incorporação de ar induzida por este aditivo. Além disso, a adição de cal influenciou no aumento da massa específica no estado fresco das argamassas, provavelmente devido ao maior empacotamento promovido pelos finos. Observou-se também uma elevada massa específica para argamassa de tratamento 1:0:6AES20, em comparação com as argamassas produzidas com cal. Tal fato pode estar relacionado ao melhor empacotamento da matriz pela melhor distribuição dos grãos de menor granulometria, bem como algum efeito filler.

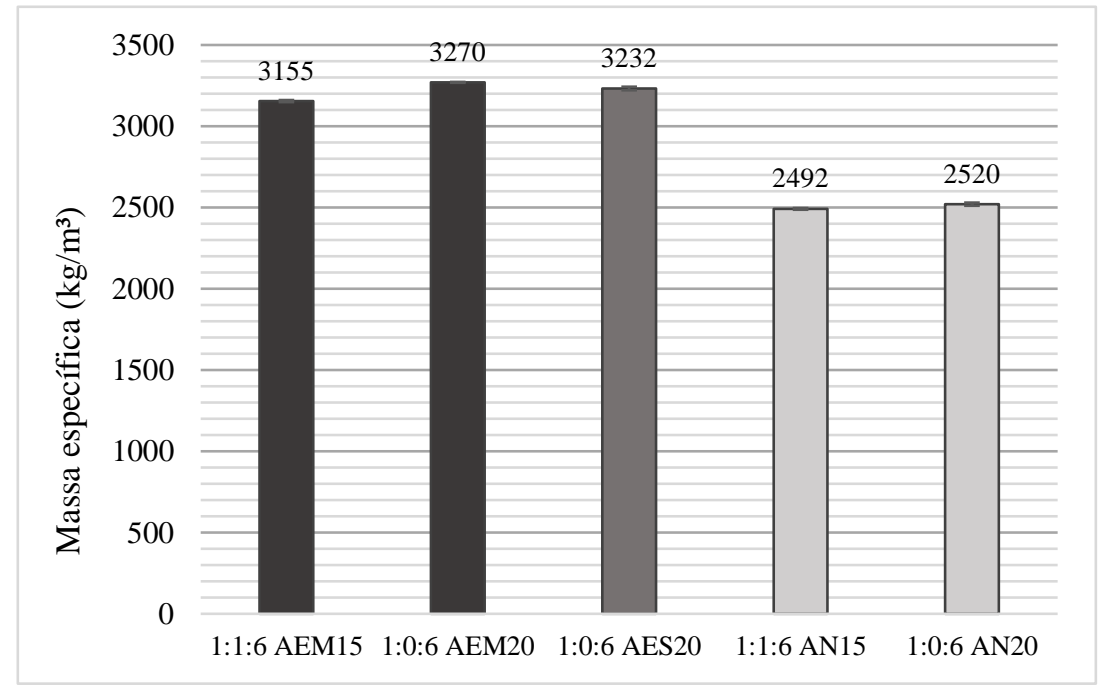

Figura 5. Massa específica das argamassas produzidas

O ensaio de adesão inicial avaliou a quantidade de argamassa aderida ao substrato padrão para cada tratamento, segundo metodologia proposta (Figura 2). Esta propriedade é fortemente influenciada pela plasticidade, coesão e tixotropia das argamassas, mas também diretamente dependente das condições do substrato em que é aplicada (absorção inicial e rugosidade). A Tabela 4 apresenta os resultados obtidos para adesão inicial das argamassas.

Tabela 4. Adesão inicial das argamassas

$\begin{array}{cc}\text { Tratamento } & \text { Adesão Inicial } \\ \text { 1:1:6AEM15 } & 88 \% \\ \text { 1:0:6AEM20 } & 82 \% \\ \text { 1:0:6AES20 } & 90 \% \\ \text { 1:1:6AN15 } & 94 \% \\ \text { 1:0:6AN20 } & 91 \%\end{array}$

A presença de cal hidratada nas argamassas influencia positivamente a reologia da matriz, contribuindo para maior retenção de água e incremento da superfície especifica da matriz, resultando em boa adesão inicial como observado pelas argamassas de tratamentos 1:1:6AEM15 e 1:1:6AN15, se comparadas as de tratamentos 1:0:6AEM20 e 1:0:6AN20, 
respectivamente. O tratamento 1:0:6AES20, não apresenta cal em sua composição, mas obteve boa adesão inicial, maior inclusive que a mistura produzida com AEM e cal. Tal resultado pode estar associado ao efeito da combinação de partículas finas e LAS. Uma maior superfície específica associada a dispersão controlada de bolhas de ar (ar incorporado) podem ter contribuído para um maior acúmulo de água, induzindo melhor adesão inicial.

Em relação à adesão inicial, as argamassas produzidas com $\mathrm{AE}$ apresentaram performance muito similar às produzidas com AN, com distorção de apenas $6 \%$ em relação ao maior e menor resultados obtidos.

A quantidade de água retida pela argamassa produz maiores tensões de aderência, melhor desempenho produtivo e maior durabilidade, função da maior formação de produtos de hidratação que resultam de fato em ligações mais fortes entre revestimento e substrato (Carasek, 2010). A Figura 6 apresenta os resultados para o ensaio de retenção de água. As argamassas com cal em sua composição apresentaram maior retenção de água.

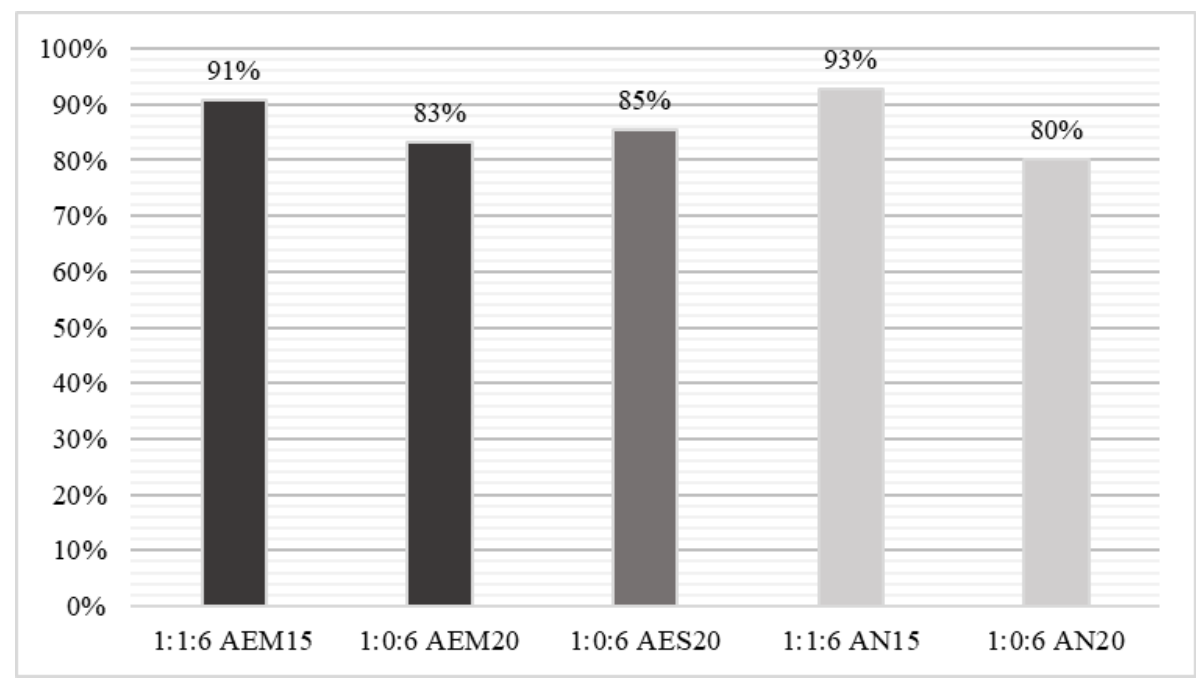

Figura 6. Retenção de água das argamassas

Destaca-se o fato de a argamassa 1:0:6AES20, apresentar retenção de água superior às demais composições também sem cal. Tal resultado é coerente, uma vez que a capacidade de retenção de água da argamassa está ligada, também, à superfície específica de seus constituintes. Além disso, por possuir uma textura superficial mais rugosa que os agregados naturais, a escória é mais susceptível à retenção de umidade (Toffolo, 2015). Uma boa retenção de água contribui para o não aparecimento de fissuras, manifestação patológica comum em argamassas de revestimento.

\subsubsection{Estado endurecido}

Os resultados obtidos para os ensaios que avaliaram a resistência mecânica das argamassas (Figura 7) indicaram que as argamassas de tratamentos utilizando a mesma areia, porém com maior teor de LAS, apresentaram resistência mecânica inferior àquelas dosadas com menor teor desse aditivo. Tal resultado pode ser justificado pelo aumento do teor de ar incorporado e do índice de vazios e, consequentemente, das descontinuidades da matriz; diminuindo, portanto, sua resistência mecânica. $\mathrm{O}$ efeito filler também pode ser o responsável pela boa resistência mecânica apresentada pela argamassa submetida ao tratamento 1:0:6AES20, comparativamente às demais composições sem cal.

O resultado de resistência à compressão obtido para a mistura utilizando-se areia de escória foi 32\% superior ao encontrado para a mesma mistura, trocando-se somente o agregado para areia natural de rio. 


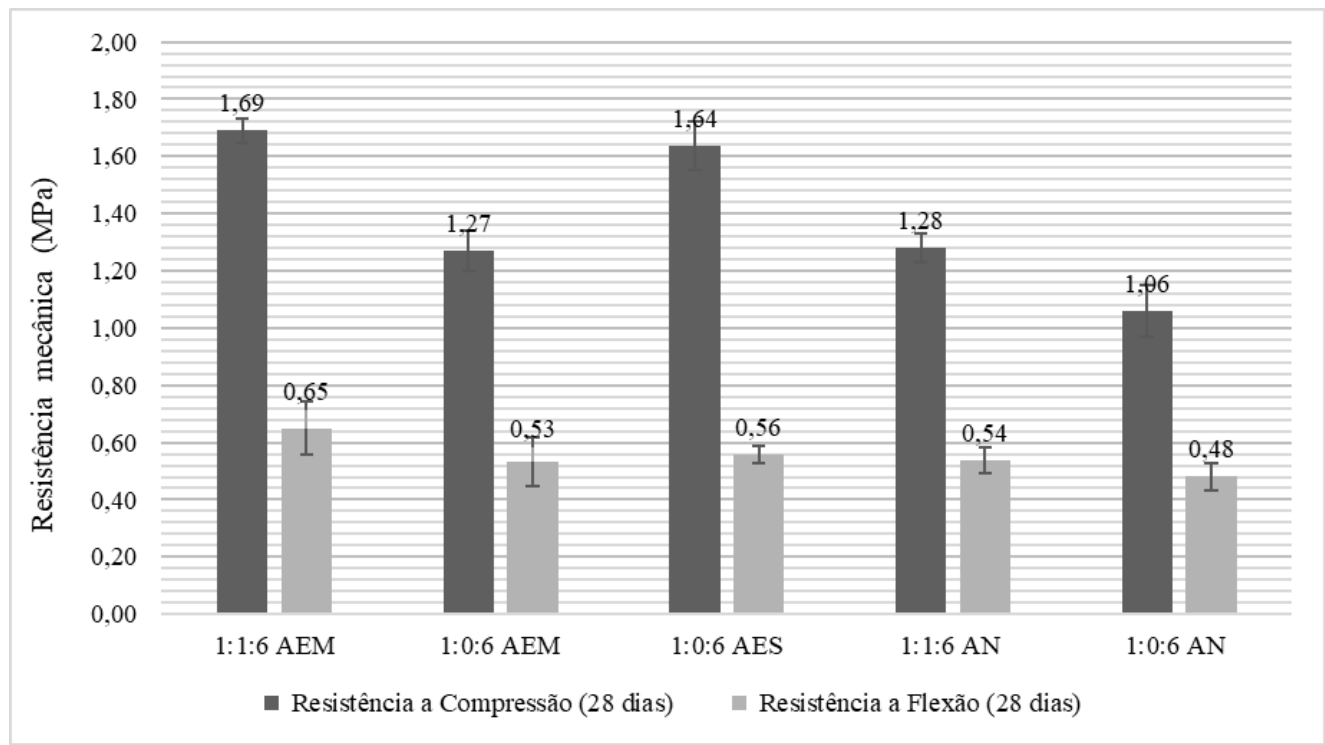

Figura 7. Resistência mecânica das argamassas

Os resultados dos ensaios de absorção de água por imersão e índice de vazios corroboraram o que foi obtido anteriormente. Ou seja, a relação do índice de vazios e da absorção de água foi inversamente proporcional à resistência mecânica, como evidenciado na Figura 8. Entretanto, quando se analisa a composição 1:0:6 AES, cuja absorção de água e índice de vazios foi superior aos demais, tal relação não pode ser aplicada. Acredita-se que isso se deva ao fato de a matriz ainda manter sua compacidade e que o índice de vazios e absorção de água se deva a pequenos poros dispersos na mesma, não prejudicando seu comportamento mecânico.

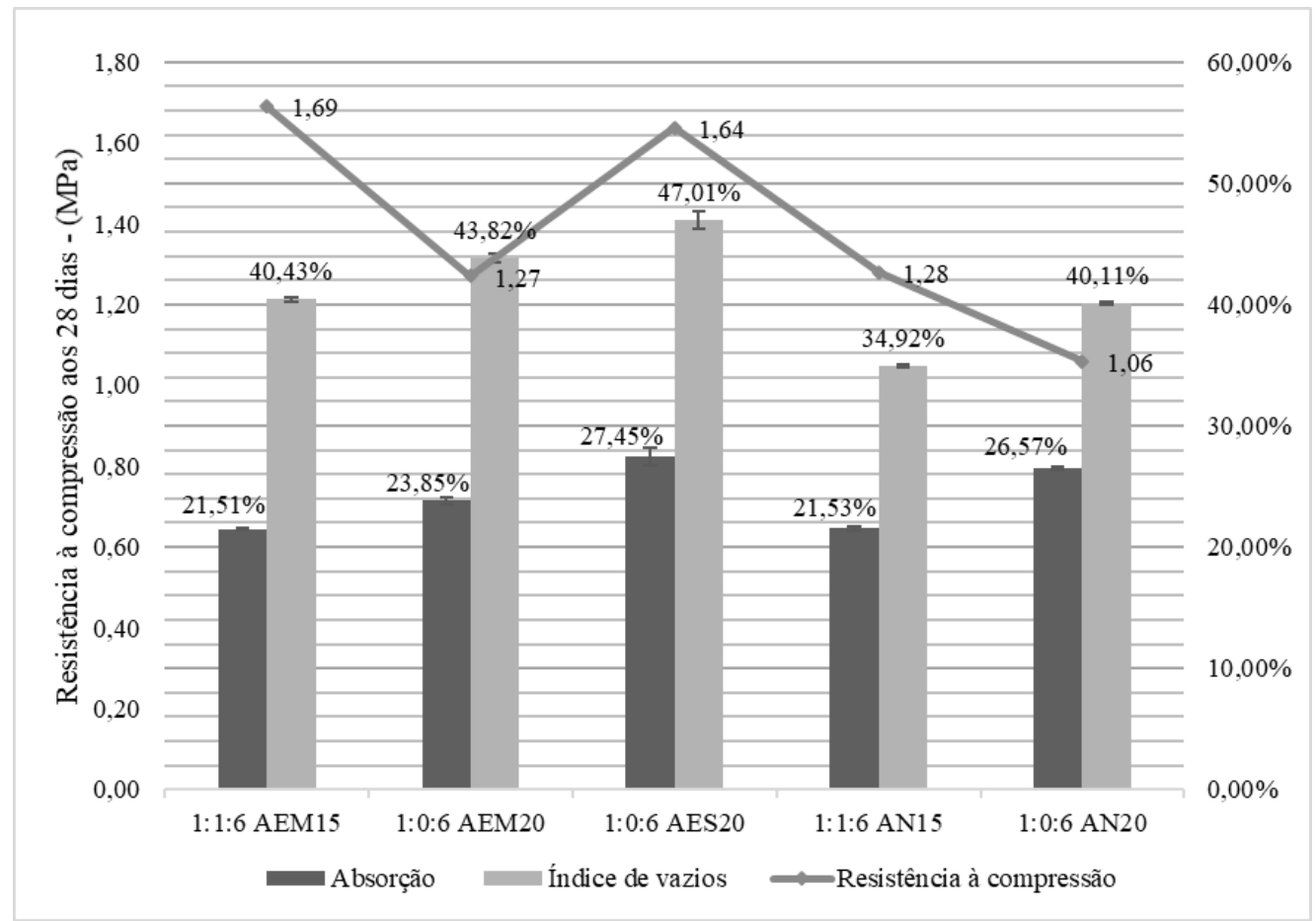

Figura 8. Comparativo: absorção, índice de vazios e resistência à compressão aos 28 dias

Tratando-se do ensaio para determinação da durabilidade pelo método acelerado, as barras produzidas com argamassas obtidas das areias de escória exibiram elevada fissuração (Figura 9) e romperam-se interrompendo a condução da técnica. Portanto, os resultados serão apresentados até os 17 dias de idade. As determinações para a variação de comprimento da barra devem ser conduzidas até 31 dias de idade idealmente, considerando o tempo de 17 dias como referência para definição para a curva de expansibilidade/retratilidade, NBR 15577-4 (ABNT, 2009). 

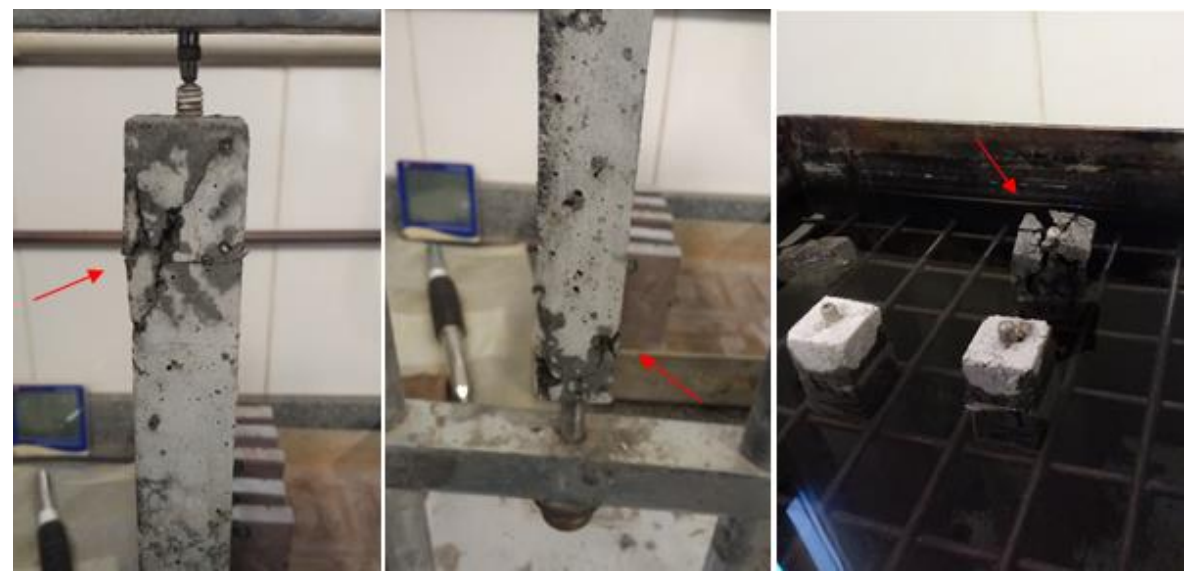

Figura 9. Manifestações patológicas nas barras produzidas com areia de escória

De acordo com a NBR 15577-1 (ABNT, 2008), um agregado pode ser considerado potencialmente inócuo se indicar expansão inferior a $0,19 \%$ aos 30 dias. O conjunto de barras produzidas com areia de escória como agregado apresentou uma expansibilidade média de 2,3\% considerados 17 dias de ensaio, conforme evidenciado na Figura 10. Desta forma, o agregado pode ser considerado como potencialmente reativo. Para o conjunto de barras produzidas com areia de rio, foi obtido através das medições realizadas, uma retração média de $0,16 \%$ (Figura 10); não deletéria e o agregado classificado como potencialmente inócuo.

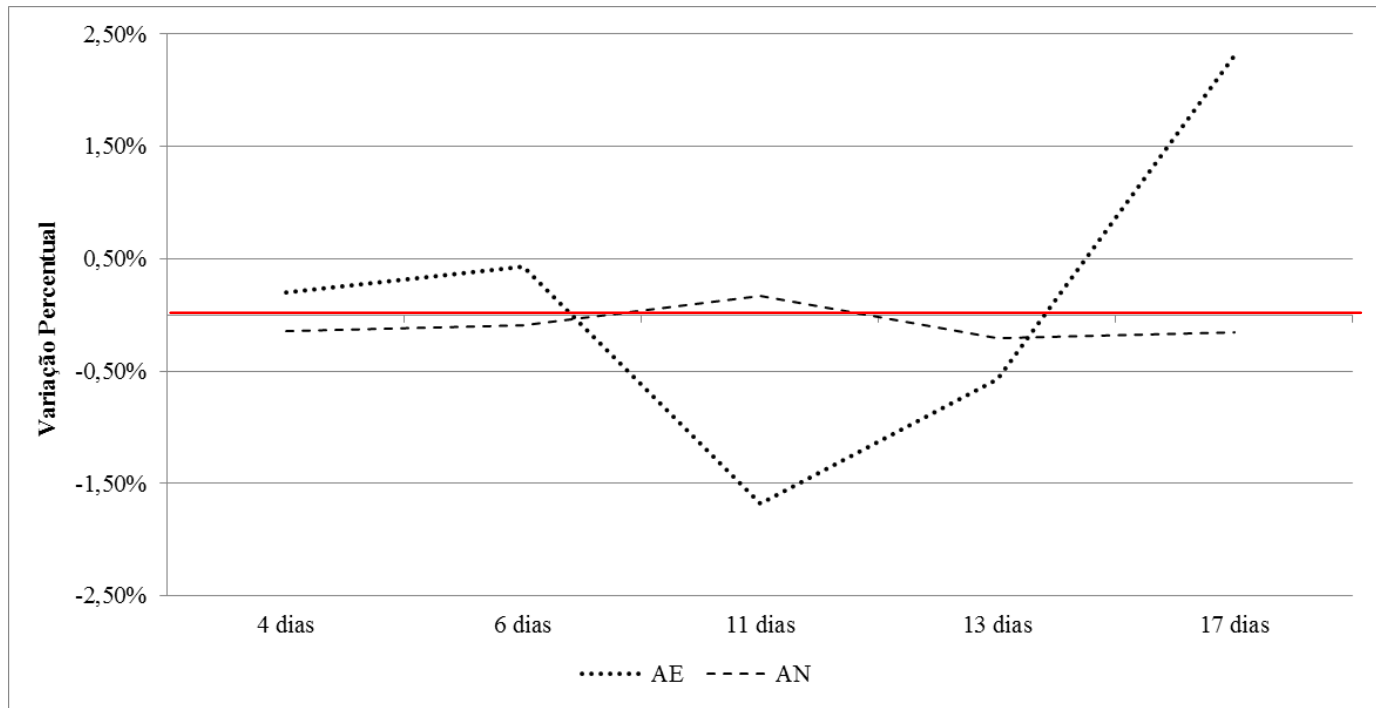

Figura 10. Variação percentual das barras produzidas com areia de escória (AE) e areia natural de rio (AN)

Em relação ao ensaio de carbonatação, houve a carbonatação de todos os corpos de prova produzidos (Figura 11). São fatores determinantes para este fenômeno: concentração de $\mathrm{CO}_{2}$, umidade relativa, temperatura, composição e permeabilidade da matriz cimentícia, entre outros. $\mathrm{O}$ fato de todas as misturas produzidas terem carbonatado, pode estar relacionado a presença de cal livre do aglomerante aéreo e à cal livre eventualmente presente nas escórias (cominuídas), quais converteram-se em carbonatos, induzidas pelo fluxo de gases pela rede de poros das mesmas, que permitiu a melhor difusão do $\mathrm{CO}_{2}$. Outros fatores também podem ter influenciado, como por exemplo, a compactação dos corpos de prova; excesso de ar aprisionado e alterações na porosidade, facilitando a penetração e propagação da frente de carbonatação. A investigação da carbonatação é de particular importância para argamassas, pois como se trata de um fenômeno de difusão, indica a suscetibilidade da matriz a receber ataques do meio externo, comprometendo a durabilidade das estruturas. 


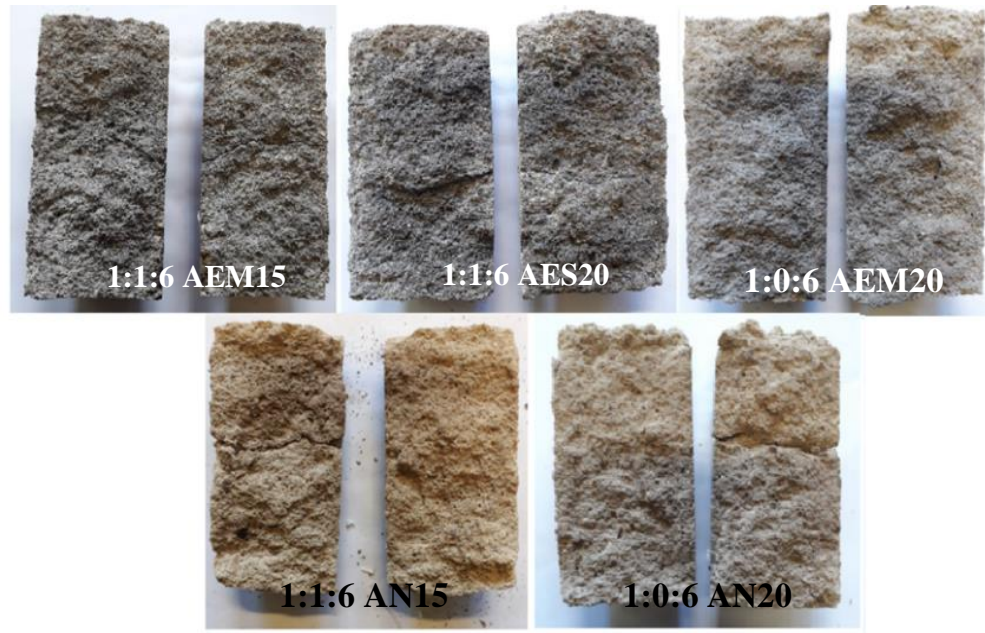

Figura 11. Corpos de prova seccionados longitudinalmente evidenciando carbonatação das matrizes (incolores após aspersão de fenolftaleína)

\section{CONCLUSÃO}

O presente trabalho avaliou a viabilidade de se produzir argamassas de revestimento utilizando-se escória de aciaria como agregado miúdo. Avaliou também a dosagem de LAS, para garantir melhorias nas qualidades reológicas da matriz, sem prejudicar seu desempenho mecânico. Nesse sentido, destacam-se a seguintes observações:

- os teores relativamente elevados de $\mathrm{Fe}_{2} \mathrm{O}_{3}$ contidos na areia produzida a partir de EA, induziram a massas específicas no estado fresco das argamassas maiores que aquelas produzidas com agregado natural;

- argamassas com maiores teores de LAS apresentaram desempenho mecânico inferior comparativamente àquelas utilizando o mesmo agregado e menor teor de LAS;

- a argamassa produzida com areia de escória na granulometria mais fina apresentou comportamento mecânico e propriedades no estado fresco superiores aos das argamassas produzidas sem adição de cal;

- observou-se que o LAS atuou melhor em material finamente disperso e que a incorporação de ar provocada pelo mesmo não afetou a resistência mecânica das mesmas, provavelmente pela existência de pequenos poros não conectados dispersos pela matriz;

- houve carbonatação das argamassas produzidas com areia de escória e areia natural de rio, indicando que a técnica para produção das mesmas, ou a quantidade de ar incorporado foi inadequada;

- a areia de escória utilizada apresentou-se como agregado potencialmente reativo, segundo ensaio de durabilidade pelo método acelerado.

O presente trabalho evidenciou a necessidade de estudos mais aprofundados a respeito da substituição de agregados naturais por agregados produzidos a partir de escória de aciaria. Pois enquanto os resultados para ensaios no estado fresco apontam para bom uso da areia de escória em substituição à areia natural de rio, os ensaios no estado endurecido para avaliação do comportamento a longo prazo das matrizes produzidas indicam o contrário.

Como esse estudo contém resultados e conclusões iniciais sobre um tema que ainda tem muito a ser discutido, espera-se que o mesmo norteie estudos futuros para utilização de novos materiais. Como efeito da utilização de areia de escória para produção de argamassas, espera-se contribuir para um menor impacto ambiental devido à disposição de coprodutos da produção do aço, e garantir o reuso destes para aplicação na construção civil e, finalmente, contribuir para o desenvolvimento sustentável.

\section{AGRADECIMENTOS}

O presente trabalho foi realizado com apoio da Coordenação de Aperfeiçoamento de Pessoal de Nível Superior - Brasil (CAPES) - Código de Financiamento 001. Os autores também agradecem à FAPEMIG, CNPq e UFOP pelo apoio para a realização e apresentação dessa pesquisa. Somos gratos ainda pela infraestrutura e colaboração do Grupo de Pesquisa em Resíduos Sólidos - RECICLOS - CNPq. 


\section{REFERÊNCIAS}

ASSOCIAÇÃO BRASILEIRA DE NORMAS TÉCNICAS. NBR 5733: Cimento Portland de alta resistência inicial. Rio de Janeiro, 1991.

ASSOCIAÇÃO BRASILEIRA DE NORMAS TÉCNICAS. NBR 1763: Aditivos para concreto de Cimento Portland. Rio de Janeiro, 1992.

ASSOCIAÇÃO BRASILEIRA DE NORMAS TÉCNICAS. NBR 9776: Agregado miúdo - Determinação da massa específica e massa específica aparente. Rio de Janeiro, 2003.

ASSOCIAÇÃO BRASILEIRA DE NORMAS TÉCNICAS. NBR 13276: Argamassa para assentamento e revestimento de paredes e tetos - Preparo da mistura e determinação do índice de consistência. Rio de Janeiro, 2005.

ASSOCIAÇÃO BRASILEIRA DE NORMAS TÉCNICAS. NBR 13277: Argamassa para assentamento e revestimento de paredes e tetos - Determinação da retenção de água. Rio de Janeiro, 2005.

ASSOCIAÇÃO BRASILEIRA DE NORMAS TÉCNICAS. NBR 13278: Argamassas para assentamento e revestimento de paredes e tetos - Determinação da Densiadade de Massa e do Teor de ar incorporado. Rio de Janeiro, 2005.

ASSOCIAÇÃO BRASILEIRA DE NORMAS TÉCNICAS. NBR 13279: Argamassa para assentamento e revestimento de paredes e tetos - Determinação da resistência à tração na flexão e à compressão. Rio de Janeiro, 2005 .

ASSOCIAÇÃO BRASILEIRA DE NORMAS TÉCNICAS. NBR 13281: Argamassa para assentamento e revestimento de paredes e tetos - Requisitos. Rio de Janeiro, 2005.

ASSOCIAÇÃO BRASILEIRA DE NORMAS TÉCNICAS. NBR 7211: Agregados para Concreto - Especificação. Rio de janeiro, 2005.

ASSOCIAÇÃO BRASILEIRA DE NORMAS TÉCNICAS. NBR NM 45: Determinação da massa unitária e do volume de vazios. Rio de Janeiro, 2006.

ASSOCIAÇÃO BRASILEIRA DE NORMAS TÉCNICAS. NBR 15577-4: Agregados - Reatividade álcali-agregado - Parte 4: Determinação da expansão em barras de argamassa pelo método acelerado. Rio de Janeiro, 2009.

ASSOCIAÇÃO BRASILEIRA DE NORMAS TÉCNICAS. NBR 15577-1: Agregados - Reatividade álcali-agregado - Parte 1: Guia para avaliação da reatividade potencial e medidas preventivas para uso de agregados em concreto. Rio de Janeiro, 2008.

AMERICAN SOCIETY FOR TESTING AND MATERIALS. ASTM C144-84: Agregate for masonry mortar. Filadélfia, 1987.

ASSOCIATION FRANÇAISE DE NORMALISATION. XP P 18-458: Essai pour béton durci - Essai de carbonatation accélérée - Mesure de l'épaisseur de béton carbonaté. Saint-Denis, 2008.

BRITISH STANDARD INSTITUTION. BS 1200: Sands for mortar for plain and reinforced brickwork, blockwork, blockwalling and masonry. Londres, 1976.

CARASEK, H. Argamassas. Materiais de Construção Civil e Princípios de Ciência e Engenharia de Materiais. São Paulo: IBRACON, 2010.

GEYER, R. M. T. Estudo sobre a Potencialidade de Uso das Escórias de Aciaria como Adição ao Concreto. 2001.188f. Tese. Escola de Engenharia, Centro de Tecnologia da Escola de Engenharia da UFRGS. Porto Alegre, RS, Brasil, 2001. 
IABR. Relatório de Sustentabilidade de 2018. Rio de Janeiro, 2018.

MENDES, J. C. et al. Mechanical, rheological and morphological analysis of cement-based composites with a new LAS - based air entraining agent. Construction and Building Materials, v.145, p.648-661, 2017.

MOURA, C. B. Aderência de revestimentos externos de argamassa em substratos de concreto: influência das condições de temperatura e ventilação na cura do chapisco. 2007. 234 f. Dissertação. UFGRS. Porto Alegre, RS, Brasil, 2007.

POLESE, M. D. O. Estudo da expansibilidade e da microestrutura de escorias de aciaria LD e EAF, 2007. $271 \mathrm{f}$. Dissertação. Universidade Federal do Espírito Santo, Vitória, ES, Brasil, 2007.

SILVA, J. P. Manual de Agregados para Construção Civil. 2 ed. Rio de Janeiro: CETEM, 2012.

SILVA, M. J. D. Elementos de Concreto para Pavimentação Produzidos com Agregados de Escória de Aciaria, 2011, 130f. Dissertação. Escola de Minas, Universidade Federal de Ouro Preto, Ouro Preto, MG, Brasil, 2011.

SOUZA, B. P. D. Aderência de Barras de Aço tipo CA em Concreto Sustentável, 2015. 97f. Dissertação. Escola de Minas, Universidade Federal de Ouro Preto, Ouro Preto, MG, Brasil, 2015.

SOUZA, E. B. D. O. E. Escórias de Aciaria e Resíduos de Concretos Refratários em Componentes de Pavimentação, 2007, 128f. Dissertação. Universidade Federal de Minas Gerais, Belo Horizonte, MG, Brasil, 2007.

TOFFOLO, R. V. M. Pavimentos Sustentáveis, 2015. 107f. Dissertação. Escola de Minas, Universidade Federal de Ouro Preto, Ouro Preto, MG, Brasil, 2015. 